\title{
OPTIMISATION OF THE SUPERCRITICAL FLUID EXTRACTION OF VETIVER ROOTS
}

\section{Sharad Maharaj ${ }^{1 *}$, Marian Watson ${ }^{2}$, David McGaw ${ }^{3}$, Shawn Thomas ${ }^{4}$ and Shivani Sonilal ${ }^{5}$}

\author{
1,3,4,5 Faculty of Engineering, The University of the West Indies, Trinidad \\ ${ }^{2}$ Faculty of Engineering, University of Trinidad and Tobago, Trinidad \\ ${ }^{1}$ Email: Sharad.Maharaj@sta.uwi.edu *(Corresponding author) \\ ${ }^{2}$ Email: marian.watson@utt.edu.tt \\ ${ }^{3}$ Email: drmcgaw@gmail.com \\ ${ }^{4}$ Email: shawn.thomas23@hotmail.com \\ ${ }^{5}$ Email: shivanisonilal@gmail.com
}

\begin{abstract}
The market projections for growth in both the essential and oleoresins market demonstrate a unique opportunity for Trinidad and Tobago to enter the business. Since an established bay tree plantation in Tobago cannot provide the raw material to operate a natural extracts plant for an entire year, the operation could be supplemented by the production of vetiver oil using vetiver roots that are grown and supplied by Tobago farmers. The chosen extraction technique is Supercritical Fluid Extraction (SFE) using carbon dioxide solvent since SFE was found to be more efficient and versatile than the traditional technique of Steam Distillation Extraction (SDE). To determine the optimum process conditions, a laboratory scale SFE programme was implemented using indigenous vetiver roots. The interactive effects of the operating parameters of pressures, temperatures and flowrates with respect to the oil yield were ascertained using Design of Experiments (DOE) which entailed the execution of 11 experimental runs. An ANOVA test produced an $\mathrm{R}^{2}$ value 0.9864 and the optimum conditions were found to be $-220 \mathrm{Bar}$ at $50^{\circ} \mathrm{C}$ at an exit $\mathrm{CO}_{2}$ flow rate of $2 \mathrm{ml} / \mathrm{min}$. The yield at this optimum condition was $4.75 \mathrm{wt}$. \% which was considerably higher than yields reported in the literature. An initial evaluation of the economic viability of the project indicated an IRR of $28 \%$, making the project well worthy of further development towards potential commercialisation.
\end{abstract}

Keywords: vetiver, SFE, $D O E$

\section{https://doi.org/10.47412/CPTO5829}

\section{Introduction}

Many plant species in the tropics secrete complex chemicals which are extracted and incorporated into various consumer products which may be classified under the following headings:

- Food Flavours

- Aromatherapy/Personal Care Products

- Perfumes

- Various other uses e.g. security sprays, insecticides, dyes and colourings 
There are two basic types of commercial plant extracts, essential oils and oleoresins. Essential oils are the volatile oils giving rise to the odour from the plant. Oleoresins however have much higher vapour pressures than the essential oils, boiling at higher temperatures.

Growing consumer preference for natural products has led to the development of novel applications in personal care and beauty products. Rapid industrialization and growing disposable incomes, particularly in emerging economies are some of the macro factors steering growth.

In addition, rising application scope on account of growing consumer awareness regarding health benefits, and negligible side effects associated with the use of plant extracts, is expected to spur their demand in the medical industry. Growing demand for aromatic flavours and fragrances in cosmetics, perfumes, as well as spa and relaxation applications is also expected to fuel demand in the coming years. Fortune Business Insights estimated the global Essential Oils market to be $\sim$ US\$7.03b in 2018 with a projection for it to increase to US $\$ 14.5 \mathrm{~b}$ by the end of 2026 [1].

This proposal relates to the development of a versatile Plant Extracts Industry in Tobago, as one approach towards diversifying the national economy away from oil and gas. In developing the proposal, it is first recognized that there is an unutilised 60 acre Bay Oil plantation which could supply the raw material to produce Bay Oil by extraction of the oil from the leaves as the base product. Bay oil is used in a number of the consumer products listed earlier. However, in order to ensure full use of the process plant at least one more product will have to be produced from the plant. There are a number of potential raw materials which can be produced in Tobago e.g. turmeric, hot peppers, basil etc., but vetiver is proposed as the second raw material in this proposal. The reason for this choice is that it can be grown easily in Tobago by small farmers on flat or sloping land, and the extracted oil is important to the personal products industry worldwide, commanding a high unit price.

Traditionally essential oils were extracted from the plant material by steam distillation, whereas oleoresins were extracted by solvent extraction techniques. The more modern method of Supercritical Fluid Extraction (SFE) whereby carbon dioxide at high pressures and slightly above ambient temperature is passed through a bed of the material as the extracting fluid, however, is much more versatile in that the technique has the capability of extracting both essential oils and oleoresins. One major positive aspect in the national scenario is that the extracting fluid, carbon dioxide, is readily available as a by-product from the petrochemical industry at Point Lisas in Trinidad. Basic background to the SFE process and its potential for exploitation in Trinidad and Tobago has been enumerated by Maharaj et al [2] elsewhere.

Several mass transfer models have been proposed for the SFE of different extraction matrices (Priyanka [3]), with a more recent approach described by Maharaj et al [4] that could be applied to this study.

In order to develop the business model to evaluate the economic potential for introducing the concept in Tobago it is necessary to have a full understanding of the extraction characteristics of the materials to be utilized in the process. The extraction characteristics of bay leaves for the plantation have been studied by Clark et al (5) who determined that the most favourable operating conditions were 150 Bar pressure and $50^{\circ} \mathrm{C}$ temperature giving a yield of commercially acceptable extract of $\sim 4 \%$.

There is some reported work on the extraction of essential oil from vetiver [5], [6], [7], [8], [9], [10], [11], [12], [13], [14], [15], [16] but the amount of oil will vary from location to location for similar material, so it is important to test the material specifically for use in the proposed plant. In addition, it is necessary to identify optimal process condition to maximize output. The work described here devises an experimental SFE programme to evaluate the extraction characteristics of indigenous vetiver and also to determine the optimal conditions for commercial extraction. These results are then used in conjunction with previous 
work on bay oil extraction to indicate whether the installation of a commercial SFE operation in Tobago might be commercially viable.

\section{Methodology}

\subsection{Raw Materials}

The vetiver roots used in the investigation were sourced in south Trinidad from a local farmer. The roots were thoroughly washed and left out in the laboratory to dry to equilibrium prior to extraction. The moisture content of the material used in the experimental programme was $\sim 7.8 \%$ as measured by the Dean and Stark toluene distillation method. The size of the material was reduced using a Wiley Mill prior to extraction.

\subsection{Apparatus}

Extraction was carried out in a Bench Scale Speed SFE Unit using carbon dioxide as the extracting fluid using a $100 \mathrm{ml}$ vessel in which $\sim 10 \mathrm{~g}$ of material was charged to the vessel at the beginning of each run. Each experiment was carried out for 120 minutes during which time the bulk of the extract was collected.

\subsection{Experimental Programme}

The experimental programme was carried out over ranges of the process variables as follows:

$$
\begin{aligned}
& \text { Pressure - } 190 \text { to } 250 \text { bar } \\
& \text { Temperature }-40 \text { to } 60 \mathrm{C} \\
& \text { Carbon dioxide flow rate }-1 \text { to } 3 \mathrm{ml} \text { per minute }
\end{aligned}
$$

A standard extraction curve was determined for each experiment by measuring the mass of collected extract every 15 minutes.

The design of the experimental programme was centred on the cause and effect relationship of a number of independent variables (factors) on the dependent variable of interest (response) [17]. This is also known as the Response Surface Methodology (RSM) which was used to determine the effect of varying pressures, temperatures and $\mathrm{CO} 2$ flowrates on the response of the yield. Design Expert version 11 was used for this analysis. The coded variables and the corresponding midpoints of the factors were placed in the software which represented the lower bounds (-1), mid-point (0) and upper bounds (1) of the conditions used which normalized the parameters. This experiment followed a factorial design where eight experiments were done with 3 repetitive runs at the mid-point to determine reproducibility of the yield. 


\section{Results}

The factors, variables and responses for these 11 experimental runs are shown in Table 1.

Table 1: Coded and uncoded levels of independent factors and yields

\begin{tabular}{|c|c|c|c|c|c|c|c|}
\hline & \multicolumn{3}{|c|}{ Coded Variables } & \multicolumn{3}{c|}{ Uncoded Variables } & \\
\hline Run $^{\mathbf{a}}$ & $\mathrm{A}$ & $\mathrm{B}$ & $\mathrm{C}$ & Temp $\left({ }^{\circ} \mathrm{C}\right)$ & Flow (ml/min) & Pressure (bar) & $\begin{array}{c}\text { Yield } \\
(\%)\end{array}$ \\
\hline $\mathbf{1}^{\mathbf{b}}$ & 1 & 1 & 1 & 60 & 3 & 250 & 4.22 \\
\hline $\mathbf{2}$ & -1 & -1 & 1 & 40 & 1 & 250 & 4.23 \\
\hline $\mathbf{3}^{\mathbf{b}}$ & -1 & 1 & -1 & 40 & 3 & 190 & 4.39 \\
\hline $\mathbf{4}$ & -1 & -1 & -1 & 40 & 1 & 190 & 1.81 \\
\hline $\mathbf{5}$ & 1 & -1 & -1 & 60 & 1 & 190 & 2.75 \\
\hline $\mathbf{6}$ & 1 & -1 & 1 & 60 & 1 & 250 & 3.41 \\
\hline $\mathbf{7}^{\mathrm{b}}$ & -1 & 1 & 1 & 40 & 3 & 250 & 3.93 \\
\hline $\mathbf{8}^{\mathbf{b}}$ & 1 & 1 & -1 & 60 & 3 & 190 & 4.64 \\
\hline $\mathbf{9}$ & 0 & 0 & 0 & 50 & 2 & 220 & 4.87 \\
\hline $\mathbf{1 0}$ & 0 & 0 & 0 & 50 & 2 & 220 & 4.90 \\
\hline $\mathbf{1 1}$ & 0 & 0 & 0 & 50 & 2 & 220 & 4.75 \\
\hline
\end{tabular}

a: Runs were done randomly. ${ }^{\text {b: }}$ waxy resins present in sample.

Table 2: Regression coefficients with corresponding $\mathrm{P}$ and $\mathrm{F}$ values

\begin{tabular}{|c|c|c|c|}
\hline Factor & Coefficient & F-value & P value \\
\hline Intercept & 4.2563 & & \\
\hline B-CO2 flow & 0.6225 & 139.1717 & 0.0003 \\
\hline C-Pressure & 0.2750 & 27.1605 & 0.0065 \\
\hline AC & -0.2150 & 16.6016 & 0.0152 \\
\hline BC & -0.4950 & 88.0000 & 0.0007 \\
\hline ABC & 0.2250 & 18.1818 & 0.0130 \\
\hline
\end{tabular}

Table 3: ANOVA analysis of model

\begin{tabular}{|c|c|c|}
\hline \multicolumn{2}{|c|}{ Model } & Yield \\
\hline \multicolumn{2}{|c|}{ F-value } & 57.8200 \\
\hline \multicolumn{2}{|c|}{$\mathbf{R}^{2}$} & 0.9864 \\
\hline \multicolumn{2}{|c|}{ Adjusted $\mathbf{R}^{2}$} & 0.9693 \\
\hline \multicolumn{2}{|c|}{${\text { Predicted } \mathbf{R}^{2}}^{2}$} & 0.8082 \\
\hline \multirow[t]{2}{*}{ Lack of fit } & F value & 6.0700 \\
\hline & $\mathrm{P}$ value & 0.1414 \\
\hline \multicolumn{2}{|c|}{ P-value } & 0.00008 \\
\hline \multicolumn{2}{|c|}{ COV (coefficient of variance) (\%) } & 3.7400 \\
\hline
\end{tabular}


This data was then analysed, ensuring the coefficient of variance for yield was less than $10 \%$. This would then generate the Pareto analysis of variance (ANOVA). From this, the significance of the factors was evaluated from the p-values where, the smaller the value, the larger the significance. As a guide, $p$-values that are less than the significance level of 0.05 are extremely significant. This data was also used to determine the regression model and the contour plots to predict the variance of the response. This was done from utilizing the final equation in terms of coded factors shown below:

$$
\text { Yield }=4.26+0.6225 \mathrm{~B}+0.2750 \mathrm{C}-0.2150 \mathrm{AC}-0.4950 \mathrm{BC}+0.2250 \mathrm{ABC}
$$

A, B, C: Coded factors for Temperature, CO2 flow rate and Pressure respectively (Table 1).

All of the extraction curves for the experiments carried out are shown in Fig. 1.

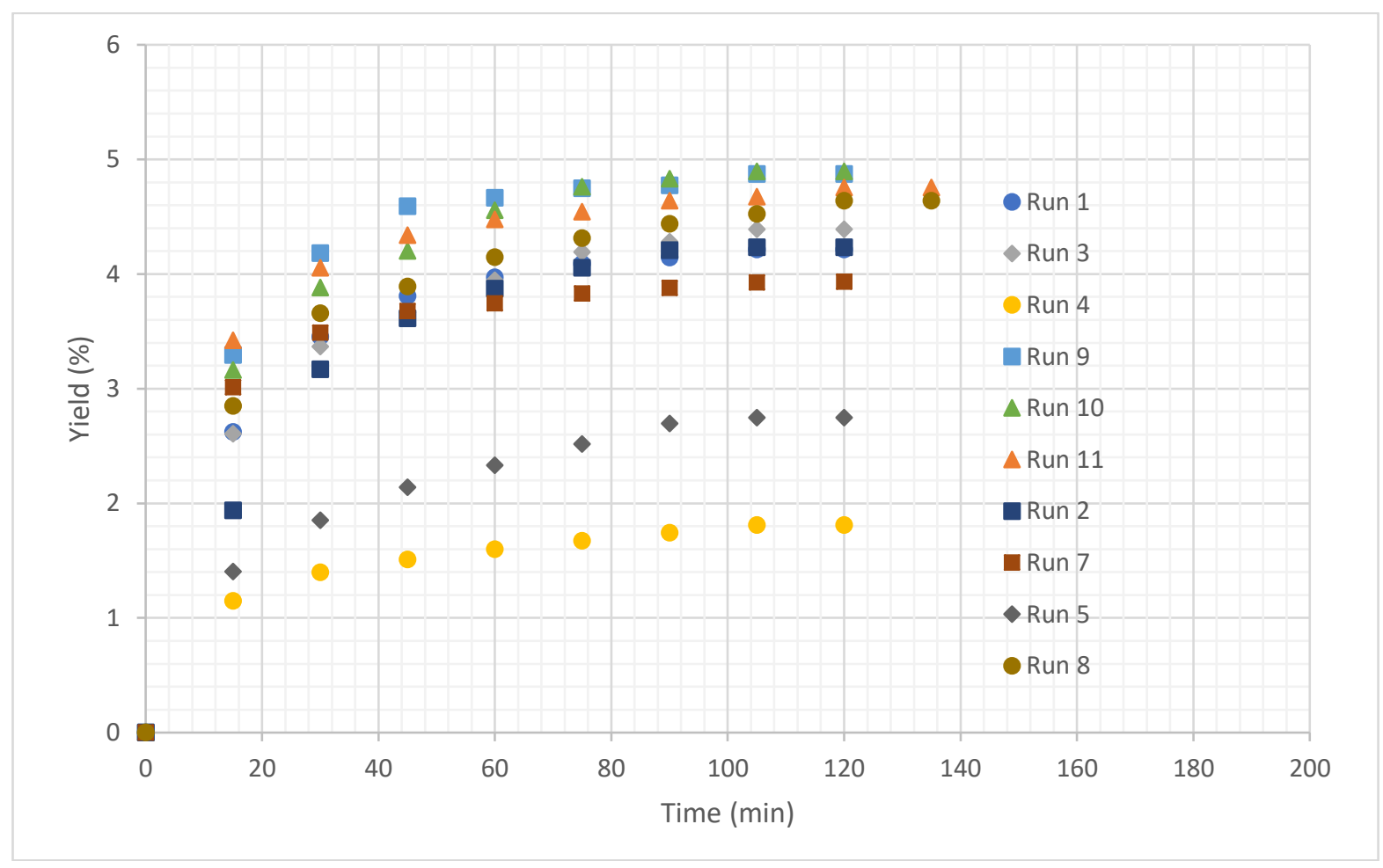

Figure 1: Percentage yields of vetiver samples vs. Time for operating conditions listed in Error!

\section{Reference source not found.1}

Reference to Fig. 1 shows a high rate of extraction at the beginning of each experiment tapering off towards the end of each experiment when all of the extract has been removed. This can be accredited to the positioning of the essential oils within the root particles. In the earlier extraction stages, the oil situated at the root's surface is removed, whereas the essential oil located deep within the cells are extracted in the progressive stages. This provides a resistance for mass transfer and hence the mass transfer rate from within the cells would be lower than that of the surface [9]. Therefore, most of the essential oil was easily available to extract at the earlier stages of extraction. 


\section{Discussion}

\subsection{Analysis of Results}

Based on the results shown in Table 2 and Table 3, a number of inferences can be made. This can be first explained by the $\mathrm{F}$ value in accordance to the $\mathrm{p}$-values. The F-value indicates whether the linear regression model proves a better fit to the data than a model with no independent variables. Therefore, the higher the value, the higher the significance, the lower the p-value and the less likely this value could occur by chance [18], [19]. The F-values for each variable were very high and hence were considered significant. This directly correlates to the significance of the $\mathrm{p}$-values. The $\mathrm{CO}_{2}$ flowrate $(\mathrm{B}: \mathrm{p}=0.0003)$ and the pressure and $\mathrm{CO}_{2}$ flowrate (BC: $\mathrm{p}=0.0007$ ) had the most significant linear and combined effect on yield respectively. But all variables investigated wielded a significant impact on yield since the p-values were all less than 0.05 . This also justified the high significance of the overall model which has a considerably low p-value of 0.00008 and a large F-value of 57.82.

Moreover, the coefficient of variance was found to be $3.7 \%$. This value was is less than $10 \%$ which implies that the deviation of data is low and applicable to the model. Additionally, the $\mathrm{R}^{2}$ value (coefficient of determination) was determined; this value is the measure of strength of the relationship between the model and the response from a scale of 0 to 1 . The closer the value tends to unity, the better the model fits the actual results [18], [9]. The value obtained from this model was 0.9864 which justified the fit of the results with respect to the model. The adjusted $\mathrm{R}^{2}$ of 0.9693 was also considerably high which indicated that the independent variables have a strong fit with respect to the model. Moreover, the difference between the predicted and the adjusted $\mathrm{R}^{2}$ was less than 0.2. This signified that there is a reasonable agreement between the two, meaning, there were no outliners [17].

With respect to the lack of fit for the model, the p-value (0.1414) illustrated that this value was not significant with respect to the pure error since it was greater than 0.05 . Therefore, the model fitted well and the equation in terms of coded factors shown above was used to create contour plots to extensively analyse and visualize the relationships between the operating factors and response.

The optimum conditions determined from the experimental programme were pressure -220 bar, temperature $-50{ }^{\circ} \mathrm{C}$ and $\mathrm{CO}_{2}$ flow rate $-2 \mathrm{ml} / \mathrm{min}$. The yield at the optimum condition was $\sim 4.75 \%$. This figure is higher than those reported in the literature where yields of 3.74\% [10], 2.9\% [16], and 3.2\% [14] were indicated.

\subsection{Implications for Commercialization}

A preliminary Techno-Economic Feasibility study for the installation of a commercial SFE plant utilizing 3 1500L extractors in Tobago has indicated that the existing Bay tree plantation would supply the plant for $\sim 110$ days per year. Allowing for vetiver supply constraints, maintenance etc. the available plant time for processing vetiver could be $\sim 185$ days per year. Using conservative estimates of $4 \%$ for bay oil extraction and $3.5 \%$ for vetiver oil extraction an initial IRR of $28 \%$ has been calculated, making the project well worthy of further development.

\subsection{Conclusions and Recommendations}

The following conclusions may be made:

1) Vetiver oil can be easily extracted from indigenous vetiver roots by Supercritical Fluid Extraction using carbon dioxide over ranges of pressure, temperature and flow rate.

2) Optimal conditions determined from the experimental programme were pressure - 220 bar, temperature $-50{ }^{\circ} \mathrm{C}$ and flow rate $-2 \mathrm{ml} / \mathrm{min}$. 
3) Optimal yield was $4.75 \%$, slightly higher than yields reported in the literature.

4) A preliminary Techno-Economic Feasibility Study for the installation of a commercial plant to produce bay oil for part of the year and vetiver oil for the remainder of the year gives an IRR of $28 \%$.

It is recommended that a more detailed evaluation of the economic potential be carried out towards potential commercialisation.

\section{References}

[1] Fortune Business Insights. 2019. Essential Oils Market Size, Share and Industry Analysis By Type (Citrus, Eucalyptus, Lavender, Rosemary, Tea Tree, and Others), Application (Food \& Beverages, Personal Care \& Cosmetics, Pharmaceuticals, and Others), and Regional Forecast 2019-2026. fortunebusinessinsights.com. https://www.fortunebusinessinsights.com/industry-reports/essential-oilsmarket-101063 (accessed January 8, 2020).

[2] S. Maharaj, M.J. Watson, R. Skeene, D.R. McGaw. 2017. Production of Plant Extracts by Supercritical Fluid Extraction. The Journal of the Association of Professional Engineers of Trinidad and Tobago 45 no. 1, (pp. 20-25).

[3] Priyanka; Khanam, S. 2018. Selection of suitable model for different matrices of raw materials used in supercritical fluid extraction process. Separation Science and Technology. 53 (pp. 71-96).

[4] S. Maharaj; D. McGaw. 2020. Mathematical Model For The Removal Of Essential Oil Constituents During Steam Distillation Extraction. Processes, vol. 8, 400.

[5] W. Clarke, D.R. McGaw, S. Maharaj. 2016. Comparison of Supercritical Fluid Extraction with Steam Distillation for the Extraction of Bay Oil from Bay (Pimenta Racemosa) Leaves. International Journal of Engineering Science Invention Volume 5 no. 1, (pp. 51-55).

[6] K.K. Chahal, U. Bhardwaj, S. Kaushal, A.K. Sandhu. 2015. Chemical composition and biological properties of Chrysopogon zizanioides (L.) Roberty syn. Vetiveria zizanioides (L.) Nash-A review. Indian Journal of Natural Products and Resources, (pp. 251-260).

[7] L.T. Danh, P. Truong, R. Mammucari, T. Tran, N. Foster. 2009. Vetiver Grass, Vetiveria zizanioides: A choice plant for phytoremeidation of heavy metals and organic wastes. International Journal of Phytoremediation (pp. 664-691).

[8] L.T. Danh, P. Truong, R. Mammucari,T. Tran, N. Foster. 2009. " Response surface method applied to supercritical carbon dioxide extraction of Vetiveria zizanioides essential oil." Chemical Engineering Journal (pp. 617-626).

[9] L. T. Danh . 2010. Supercritical CO2 Extraction of vetiver essential oil \& Economic incentive for use of vetiver grass in phytoremediation. PhD Thesis. Sydney: University of New south Wales.

[10] L.T. Danh, P. Truong, R. Mammucari, N. Foster. 2010. Extraction of vetiver essential oil by ethanolmodified supercritical dioxide. Chemical Engineering Journal (pp. 26-34).

[11] D. Emishaw. 2017. Extraction, Optimization and Characterization of Essential oil from Vetiver (Vetiveria zizanioides) Grass Root by Steam Distillation for Perfume Application. MSc Thesis. Addis Ababa: Addis Ababa University.

[12] A. Kadarohman, R. EkoS., G. Dwiyanti, L. Lailatul K.,E. Kadarusman, and A. Nur F. 2014. Quality and Chemical Composition of Organic and Non-Organic Vetiver Oil. Indonesian Journal of Chemistry 14 no. 1 , (pp. 43-50).

[13] B. Leite. 2012. Extraction Of Essential Oils from Vetiver (Vetiveria zizanioides) Grass. MSc Thesis. Durban: University of Kwazulu Natal

[14] J. Martinez, P.T.V. Rosa, C. Menut, A. Leydet, P.E Brat, D.E Pallet, M.A. Meireles. 2004. Valorization of Brazilian Vetiver (Vetiveria zizanioides). Agricultural and Food Chemistry (pp. 6578-6584).

[15] P. Pripdeevech, S. Wongpornchai ,A. Promsiri. 2006. Highly Volatile Constituents of Vetiveria zizanioides Roots Grown under Different Cultivation Conditions. Molecules 11 no.10, (pp. 817-826). 
[16] E. Talansier, M.E.M. Bragaa, P.T.V. Rosaa, D. Paolucci-Jeanjean, M.A. Meireles. 2008. Supercritical fluid extraction of vetiver roots: A study of SFE kinetics. The Journal of Supercritical Fluids 47 no.2 (pp. 200-208).

[17] Corporation, ReliaSoft. 2015. Experiment Design and Analysis Reference. Arizona: ReliaSoft Corporation.

[18] J. Frost. 2019. Statistics by Jim. statisticsbyjim.com. https://statisticsbyjim.com/regression/regressiontutorial-analysis-examples/\#more-2615 (accessed December 1, 2019).

[19] P.J. Whitcomb, M.J. Anderson. 2015. DOE Simplified. 3rd Edition. New York: CRC Press. 